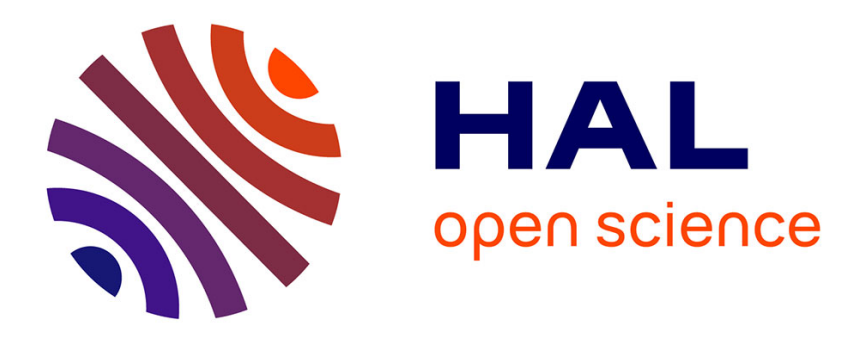

\title{
A proposal for the reconstruction of buried defects from photothermal images
}

U. Seidel, H. Walther, J. Burt

\section{To cite this version:}

U. Seidel, H. Walther, J. Burt. A proposal for the reconstruction of buried defects from photothermal images. Journal de Physique IV Proceedings, 1994, 04 (C7), pp.C7-551-C7-554. 10.1051/jp4:19947129 . jpa-00253183

\section{HAL Id: jpa-00253183 https://hal.science/jpa-00253183}

Submitted on 1 Jan 1994

HAL is a multi-disciplinary open access archive for the deposit and dissemination of scientific research documents, whether they are published or not. The documents may come from teaching and research institutions in France or abroad, or from public or private research centers.
L'archive ouverte pluridisciplinaire HAL, est destinée au dépôt et à la diffusion de documents scientifiques de niveau recherche, publiés ou non, émanant des établissements d'enseignement et de recherche français ou étrangers, des laboratoires publics ou privés. 


\title{
A proposal for the reconstruction of buried defects from photothermal images
}

\author{
U. Seidel, H.G. Walther and J.A. Burt* \\ Institut für Optik und Quantenelektronik, Friedrich-Schiller-Universität, Max-Wien-Platz 1, \\ 07743 Jena, Germany \\ * York-University, Department of Physics and Astronomy, 4700 Keele Street, North York, Canada, \\ M3J IP3
}

\begin{abstract}
The object reconstruction from synthesized and noisy photothermal signals was carried out by deconvoluting contrast scans by means of photothermal point spread function. The unknown defect depth parameter was estimated by minimizing the "imaginary content" of the deconvoluted real valued defect distribution. The algorithm shows remarkable accuracy even in the presence of $10 \%$-noise in finding the true defect depth. Essential for its convergence is an effective noise suppression which we achieved by a modified Wiener filter.
\end{abstract}

\section{Introduction}

Photothermal techniques make it possible "to see" under the surface of opaque samples. Due to the diffusive nature of thermal waves and their mutual interference the images of buried objects are blurred. Resemblance between image and object fades out with increasing depth of the object.

At photothermal imaging there arises the necessity to reconstruct buried defects from photothermal images. Recently some efforts are reported to solve this problem eg.[1]. Here we present a first attempt to make use of the photothermal point spread function as defined in [2] for object reconstruction. The method is based on the property of the photothermal image which can be expressed mathematically as a convolution integral of the point spread function $G$ and a distribution function $D$ of thermal inhomogeneities. Then the measurable photothermal contrast as defined in [3] can be written as

$$
\frac{\Delta S\left(x, y, z_{0}\right)}{S_{0}}=G\left(x, y, z_{0}\right) \otimes D\left(x, y, z_{0}\right)
$$

We have to keep in mind that $\mathrm{G}$ depends on both the defect depth and the kind of thermal inhomogeneity (thermal conductivity and/or thermal density).

Below we restrict our considerations on two-dimensional thermal patterns whose extension in depth are small compared with their distance to sample surface or with thermal diffusion length.

\section{Reconstruction of buried thermal inhomogeneities}

\subsection{Generation of the signals}

In the following section we will consider the generation of "synthetic" photothermal signals by the photothermal PSF. We generate those signals by spatially convolving the object distribution $\mathrm{D}\left(\mathrm{x}, \mathrm{y}, \mathrm{z}_{0}\right)$ with the PSF $G\left(x, y, z_{0}\right)$ given in [2] in order to simulate a scan across an infinitely thin stripe shaped defect of width $2 R$, infinitely extended in $x$ direction and buried at depth $z_{0}$ [3]. So, the defect is only 
a $2 \mathrm{D}$ rather than a $3 \mathrm{D}$ object although it exists in a $3 \mathrm{D}$ domain.

$$
D\left(y, z_{0}, R\right)=\Phi(y+R)-\Phi(y-R)
$$

where $\Phi$ is the Heaviside function. We generate the photothermal signal in terms of the amplitude contrast $\mathrm{K}_{\mathrm{A}}$ and phase contrast $\mathrm{K}_{\varphi}$. In order to meet real conditions, under which photothermal experiments are carried out, one has to involve a certain amount of noise in the synthesized signal. We did this by adding an independently, uncorraletedly and uniformly distributed noise to amplitude and phase. Its value was set to a certain percentage of the contrast value just above the center of the defect. Figure 1 shows a typical contrast signal in amplitude and phase, obtained by the spatial convolution of a defect distribution $\mathrm{D}\left(\mathrm{y}, \mathrm{z}_{0}=1, \mathrm{R}=2\right)$ with an overlaid noise of $10 \%$. These kinds of "synthesized" signals are the starting point for the proposed procedure of deconvolution.

\subsection{Deconvolution of photothermal signals by means of the photothermal PSF}

As the "measured" complex valued contrast $\mathbf{K}=\mathrm{K}_{\mathrm{A}}+\mathrm{iK}_{\varphi}$ is thought of being the result of a convolution, in principle, we can obtain the object distribution by appropriate deconvolution. By Fourier transforming all mathematical expressions (are labeled by indexes FT) $\mathrm{D}_{\mathrm{FT}}$ can be obtained as ratio $\mathrm{K}_{\mathrm{FT}} / \mathrm{G}_{\mathrm{FT}}$. But, in reality, there are at least 2 problems:

1) $\mathbf{K}$ results from noisy measurements.

2) Both defect depth $z_{0}$ and defect type are usually unknown and have to be estimated by the reconstruction procedure.

To overcome these difficulties we write

$$
D_{F T}\left(k_{x}, k_{y}, z_{0}\right)=\frac{D_{F T}\left(k_{x}, k_{y}, z_{0}\right) \cdot G_{F T}\left(k_{x}, k_{y}, z_{0}\right)}{G_{F T}\left(k_{x}, k_{y}, z_{k}\right)+W F}
$$

The summand WF in the denominator represents a modified Wiener filter, its significance for the deconvolution process will be discussed in section 2.4 .

Obviously, we only obtain the true defect distribution $\mathrm{D}\left(\mathrm{x}, \mathrm{y}, \mathrm{z}_{0}\right)$ as the Fourier back transform of $D_{\mathrm{FT}}\left(\mathrm{k}_{\mathrm{x}}, \mathrm{k}_{\mathrm{y}}, \mathrm{z}_{\mathrm{o}}\right)$ if we deconvolute it with the correct $\mathrm{G}_{\mathrm{FT}}\left(\mathrm{k}_{\mathrm{x}}, \mathrm{k}_{\mathrm{y}}, \mathrm{z}_{\mathrm{k}}\right)$, taken at the correct depth $\mathrm{z}_{\mathrm{k}}=\mathrm{z}_{0}$ assuming the same thermal type of defect in numerator and denominator. Usually, these values are unknown and we have to determine the correct $G_{\mathrm{FT}}\left(\mathrm{k}_{\mathrm{x}}, \mathrm{k}_{\mathrm{y}}, \mathrm{z}_{\mathrm{k}}\right)$ from an independent criterion.

\subsection{The deconvolution criterion}

In order to obtain the correct defect distribution as the result of the deconvolution process one has to use such a $\mathrm{G}_{\mathrm{FT}}\left(\mathrm{k}_{\mathrm{x}}, \mathrm{k}_{\mathrm{y}}, \mathrm{z}_{\mathrm{k}}\right)$ in the denominator of equ.(3) which is as close as possible to the one corresponding to the actual inhomogeneity under test. One could repeat the deconvolution process with varying parameters in the denominator and so try to look for the best match. For simplicity, we restrict our efforts to the search of the unknown defect depth $z_{0}$ and deconvolute the "measured" contrast $K\left(x, y, z_{0}\right)$ with a number of PSF's taken at guessed depths $z_{k}$. Scanning across the subsurface inhomogeneity measuring at $\mathrm{N}$ sample points $\mathrm{y}_{\mathrm{i}}$, assuming a certain depth $\mathrm{z}_{\mathrm{k}}$ for each scan, we monitor the imaginary content of deconvoluted defect by a function

$$
r m s\left(z_{k}\right)=\sqrt{\sum_{i=1}^{N}\left\{\operatorname{Im}\left[D\left(y_{i}, z_{k}\right)\right]\right\}^{2}}
$$

Because $\mathrm{D}\left(\mathrm{x}, \mathrm{y}, \mathrm{z}_{0}\right)$ has to be a real valued function we will find the correct depth $\mathrm{z}_{\mathrm{k}}=\mathrm{z}_{0}$ if $\operatorname{rms}\left(\mathrm{z}_{\mathrm{k}}\right)=$ 0 or, in the presence of noise, $\operatorname{rms}\left(z_{k}\right)$ reaches a minimum among the various depths investigated. Numerically, this means to find the global minimum of the pointwise function $\mathrm{rms}=\mathrm{rms}\left(\mathrm{z}_{\mathrm{k}}\right)$. 


\subsection{Noise suppression}

The proposed deconvolution procedure is very sensitive to noise and strongly needs a mechanism to suppress spikes in the deconvoluted result, which lead to a total loss in information after $\mathrm{D}_{\mathrm{YT}}\left(\mathrm{k}_{\mathrm{x}}, \mathrm{k}_{\mathrm{y}}, \mathrm{z}_{0}\right)$ was Fourier transformed into $\mathrm{D}\left(\mathrm{x}, \mathrm{y}, \mathrm{z}_{0}\right)$. We follow the approach in [4] using the modified Wiener Filter in the denominator of equation 3 . Adding a summand WF to the denominator prevents it from being too small. This kind of noise suppression can be derived from optimal Wiener filtering providing the noise has a white frequency dependence [5]. The constant WF reflects the power spectrum of the noise involved and has to be chosen appropriately. Figures $2 b, c$ show the result of under- and over-filtering. Choosing the filter constant WF too small (under-filtering) results in a increase of noise in the deconvolution result making it impossible to recognize the shape of the defect and leading to a decrease in accuracy in determining the depth $z_{0}$. Over-filtering (WF too large) leads to smoothing out the defect distribution, it is not longer possible to determine the shape or size of the defect, although its depth $z_{0}$ is found with reasonable accuracy.

Additional investigations also showed, that the deconvolution results only weakly depend on WF over a wide range, i.e. the choice of WF matching the power spectrum of the noise is not critical for the performance of the deconvolution algorithm. We could achieve reasonable results even for noise levels of about $10 \%-20 \%$, a range which certainly covers the common experimental conditions.

Fig.1 Calculated photothermal contrast of a stripe shaped k-inhomogeneity of width $2 \mathrm{R} / \mu$ buried at depth $z_{0} / \mu$. Abscissa is scan path.
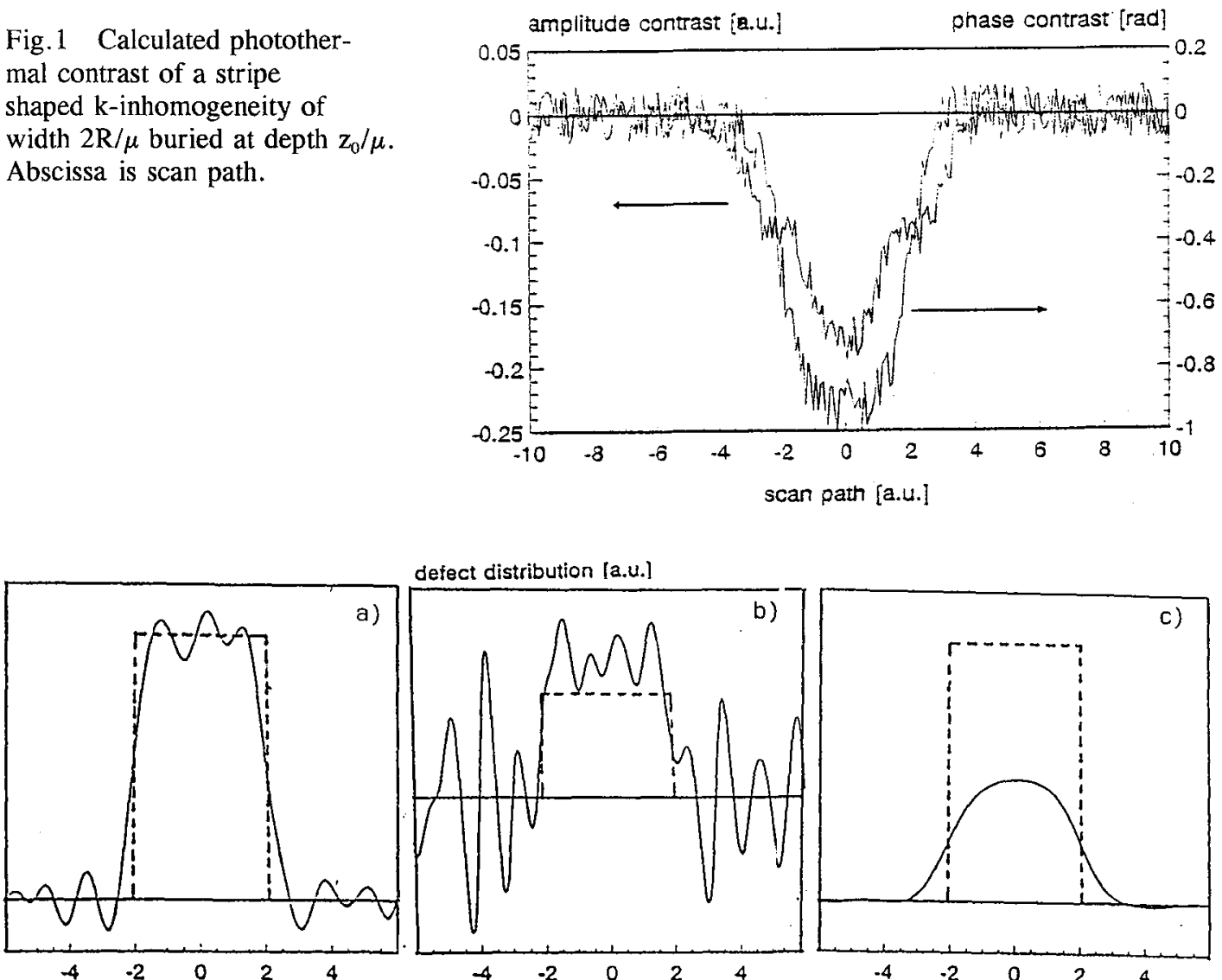

defect distribution la.u.]

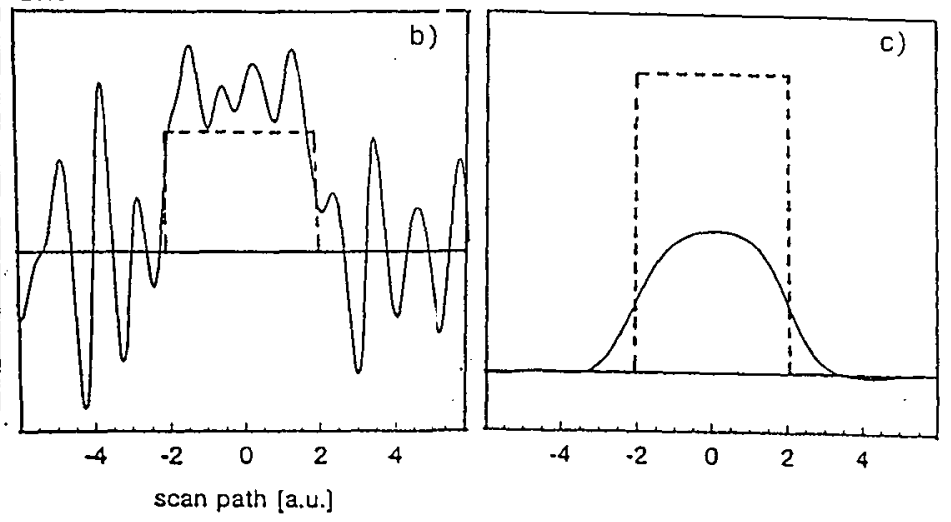

Fig.2 Object reconstruction from data of Fig. 1 using different values WF. (a: $W F=0.01, b$ : WF $=$ $0.0001, \mathrm{c}: \mathrm{WF}=1$ ). 


\subsection{Selected examples}

Object reconstructions from buried stripe shaped inhomogeneities are reported. If the true type of thermal distortion is assumed then the true defect depth can be estimated with \%-accuracy. If the type of thermal distortion is unknown an increase in uncertainty of reconstruction the size (as shown in Fig.3) and depth results.
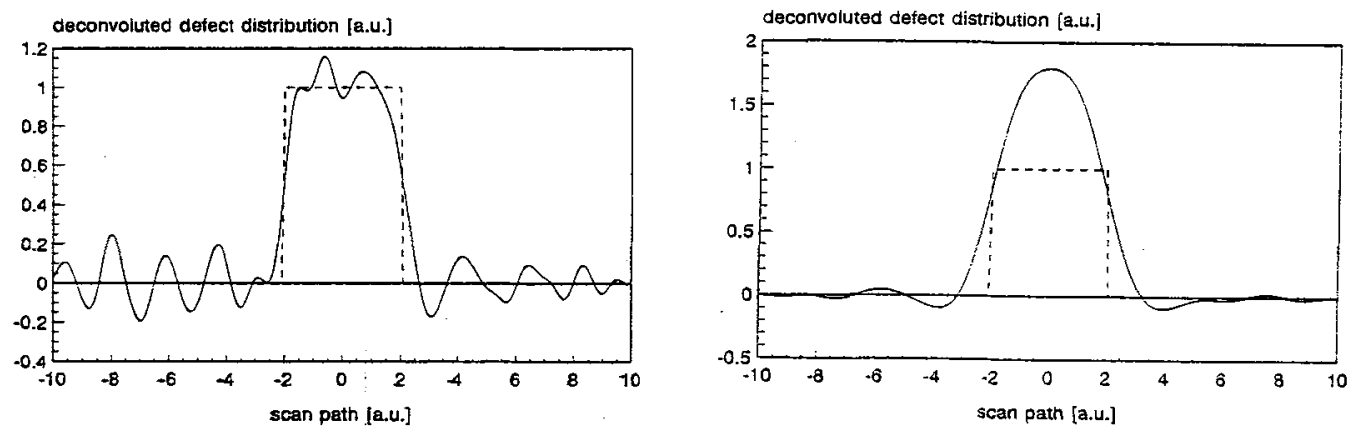

Fig.3 Reconstructed k-inhomogeneity in case of correct (left) and incorrect (right) assumption of the type of thermal distortion.

\section{Limits and further development of the suggested method}

Certainly the major drawback of the proposed method of inverting photothermal images is that one has to assume the general shape of the defect before carrying out the deconvolution. That means in the presented case of an indefinitely extended strip in $\mathrm{x}$-direction to assume this geometry in order to use the 1D-PSF. Also, so far we have developed the method only for very thin defects (in terms of $\mu$ ). The extension to real 3D defects is assumed to involve mathematical difficulties in deriving a 3D-PSF.

Furthermore, it seems to be difficult to distinguish clearly between $k$ - and $(\rho c)$-defects at this level of theory. For further improvements one has to make use of the knowledge of the frequency dependence of $\mathrm{G}\left(\mathrm{x}, \mathrm{y}, \mathrm{z}_{0}\right)$ and the signal.

The next step will be the extension of the algorithm to higher dimensions. The presented case is a semi$2 \mathrm{D}$ problem, but even the application to disk shaped defects would require a 2D-PSF and therefore 2DFourier transformation.

Additional difficulties will be encountered if we proceed with real measurements instead of the synthesized signals described above. Problems will arise from calibrating the depth and frequency axes by applying the deconvolution algorithm on real measurements.

The authors wish to acknowledge the financial support of the Deutsche Forschungsgemeinschaft (DFG) and the Deutscher Akademischer Austauschdienst (DAAD).

[1] D.J.Crowther, L.D.Favro, P.K.Kuo, R.L.Thomas, "Inversion of Pulsed Thermal Wave Images for Recovery of the Shape of the Object", Proc.7th.Int.Top.Meeting on Photoacoustic and Photothermal Phenomena III, Doorwerth, Aug.26-30, 1991

[2] K.Friedrich, K.Haupt,U.Seidel,H.G.Walther, J.Appl.Phys. 72 (1992), 3759-3764

[3] U.Seidel, K.Haupt, H.G.Walther, J.Burt, B.K.Bein, J.Appl.Phys. 75 (1994), No. 8

[4] W.Braun, I.Price, B.C.Cadoff and N.C. Peterson, International Journal of Chemical Kinetics 21 (1989), 1029

[5] W.H.Press, B.P.Flannery, S.A.Teukolsky, W.T.Vetterlein, Numerical Recipes in Pascal, Cambridge University Press, Cambridge (UK), 1989 